\title{
Subdural Hematoma and Delirium case evaluation in elderly patients
}

\author{
Abdalla Al-Khateeb ${ }^{1}$, Muaed Jamal Alomar ${ }^{2}$ \\ 'Department of Clinical Pharmacy, Ajman University of Science and Technology; Ajman, UAE. \\ 2Department of Clinical Pharmacy, College of Pharmacy and Health Sciences, Ajman University of Science and Technology; Ajman, UAE.
}

\begin{abstract}
Objective: A common and serious acute neuropsychiatric syndrome with core features of inattention and global cognitive dysfunction called delirium can be associated with subdural haematoma (SBD) following a minor trauma in elderly. The objective is to study the medication problems of a patient suffering from subdural haematoma. Method: case report and analysis. Result: Direct Head trauma is absent in the history of this case as the chief complaint and reason of admission to the hospital is the hip fracture complaint. The common manifestations are altered mental state and focal neurological deficit. At the time of diagnosis the neurological state is important because delirium might be misdiagnosed. Pharmaceutical care strategies for both delirium and SBD are implanted and the result shows that the treatment plan although it may improve the illness condition but associated with various risks. Some medications are interacting with others or contraindicated in concurrent diseases, medications used with no apparent current indication along with using inappropriately high or low medicine dosages or duplicate medication without monitoring adverse reactions of drugs. Conclusion: Effective and safe administration of
\end{abstract}

medicines in elderly patients is essential. Standards considering concomitant disease states and medications will ensure and enhance the therapeutic outcomes.

Key words: Hematoma, Delirium, Valium, Ischemic, Pharmaceutical-Care. Key message: The use of medications in case of subdural haematoma should be minimized to avoid any possible adverse drug reactions.

\section{Correspondence :}

Muaed Jamal Alomar,

Clinical Pharmacy Department, College of Pharmacy and Health Sciences, Clinical pharmacoinformatics; Clinical Pharmacy Lecturer; Ajman University of Science and Technology; Ajman, UAE.

Phone no: 00971507157641

Email: muayyad74@yahoo.com, m.alomar@ajman.ac.ae.

DOI: 10.5530/jyp.2017.9.59

\section{INTRODUCTION}

Chronic subdural haematoma (CSDH) is an encapsulated collection of old blood, mostly or totally liquefied and located between the dura mater and arachnoid. CSDH should be differentiated from acute subdural haematoma. Acute subdural haematomas generally occur in younger adults, after a major trauma, often associated with structural brain injury, and present within $72 \mathrm{~h}$. In contrast, CSDHs often occur in the elderly after a trivial injury without any damage to the underlying brain and usually there is a period of weeks to months before it becomes clinically evident. ${ }^{1}$ Generalized cerebral atrophy and increased venous fragility associated with aging are the major predisposing factors. ${ }^{2,3}$

Avoidable adverse drug events are the serious consequences of inappropriate drug prescribing. The possibility of an adverse drug event should always be borne in mind when evaluating an older adult individual; any new symptom should be considered drug-related until proven otherwise. Prescribing for older patients presents unique challenges. Premarketing drug trials often exclude geriatric patients and approved doses may not be appropriate for older adults. ${ }^{4}$

\section{METHOD}

Case report of a 65 years old Indian female admitted to a hospital in UAE with hip fracture as chief complaint, she has other complaints including drowsiness, altered mental status, agitation, cold, shaking, shouting, severe coughing, wheezing, shortness of breath and wheezing. She has history of uncontrolled hypertension for more than 15 years, and diabetes for more than 10 years, then hyperlipidemia and recently ischemic heart disease with a social history of smoking and she is a heavy alcohol drinker with no known drug allergy. Medications history include Aspirin $100 \mathrm{mg}$ OD for anti-clotting effect, Patient was on Maprotiline $25 \mathrm{mg}$ twice daily for the relief of anxiety associated with depression. The usual geriatric dose for maintenance for outpatients with mild to moderate depression is 50 to $75 \mathrm{mg}$ as a single or divided daily dose which is usually satisfactory for patients over 60 years of age. Insulin Glargine, an ultralente long-acting insulin titrated up to 26 units daily with Insulin Regular of 8 units TID.

On physical examination, BP was 175/80 mm of hg, HR-100 bpm, T-37.60C, Wt -80 kg, and Ht- 5'7', while RR- 32 (12-18 breaths per minute). On chest examination, numerous rales (moist, dry, fine, and course), rhonchi (Sounds that resemble snoring), and wheezes had been noticed, Skin Color is Pale or yellowish on admission. The patient was given diazepam $5 \mathrm{mg}$ IV to control the hypertension crisis on admission. Chest x-ray showed signs of pneumonia; Head CT scan confirms subdural hematoma and delirium. Fibrotic lung on lung X-ray and she also diagnosed as having broncho pneumonia. Hip X-ray confirms the former fracture, Stomach CT scan is normal. No hormonal changes have been documented. Other lab values are in Table 1, Fasting Blood Glucose readings given by Table 2 .

After admission Enoxaparin $40 \mathrm{mg}$ SC OD daily has been prescribed which has low molecular weight of heparin as anticoagulant used to prevent deep vein thrombosis (DVT). Simvastatin also of $20 \mathrm{mg}$ OD daily as a lipid-lowering medication. The dose of insulin increased to 
be insulin Glargine 26 units daily and 24 units of regular insulin TID. Phenytoin $100 \mathrm{mg}$ BID daily as prophylactic anticonvulsive medication (ACM) for occurrence of seizures was given also.

\section{DISCUSSION}

CAM, Confusion Assessment Method is the most widely used screening test for the presence of delirium; a four-item instrument based on Diagnostic and Statistical Manual of Mental Disorders (DSM-III-R) delirium criteria, requires the presence of acute onset and fluctuating course, inattention, and disorganized thinking or loss of consciousness. ${ }^{5}$ CAM should be considered in the diagnosis.

Enoxaparin is a low-molecular weight heparin used to prevent deep venous thrombosis in patients undergoing total hip or knee arthroplasty. Anticoagulation in a patient after trauma may be dangerous and lead to significant hemorrhage. Although enoxaparin has been shown to be an effective and safe drug for venous thromboembolism prophylaxis in orthopedic surgeries and trauma, severe bleeding may rarely occur, especially in the setting of head trauma. Other therapies for venous thromboembolic prophylaxis, such as mechanical thromboembolism prophylaxis methods, should be considered. ${ }^{6}$

For Convulsion treatment, Levetitracetam, $500 \mathrm{mg}$ BID reducing neurotransmitter release and acting as a neuromodulator was given to the patient, adjustment of the dose is recommended in elderly patients according to creatinine clearance and that was not done. Levetiracetam, along with other anti-epileptic drugs, can increase the risk of suicide behavior or thoughts. People taking levetiracetam should be monitored closely for signs of worsening depression, suicidal thoughts or tendencies, or any altered emotional or behavioral states. ${ }^{7}$ Phenytoin: $500 \mathrm{mg}$ IV OD was given also for convulsion.

To treat Delirium, the patient was on Quetiapine 50-300 mg/day, Quetiapine results in faster delirium resolution, less agitation, and a greater rate discharge or rehabilitation. ${ }^{9}$ Citalopram $10 \mathrm{mg}$ OD was given too.

To treat Subdural Hematoma Furosemide $40 \mathrm{mg}$ OD and Mannitol $20 \%$ IV BID were given. Mannitol and furosemide have a synergistic effect when combined; however, this combination tends to cause severe electrolyte disturbances. ${ }^{10}$ For Pneumonia Itraconazole $100 \mathrm{mg}$ OD was given.

Studies show that Itraconazole is more effective than fluconazole against Aspergillus pneumonia. ${ }^{8}$

Patient was prescribed Quetiapine $1 / 2$ tablet $25 \mathrm{mg}$ OD for delirium (most likely) as attempt of tapering trial of the medication once symptoms are in control. Discontinue newer neuroleptics medications such as quetiapine must be as soon as possible. Attempt a trial of tapering the medication once symptoms are in control. Neuroleptics can be associated with adverse neurological effects such as extrapyramidal symptoms, neuroleptic malignant syndrome, and tardive dyskinesia. ${ }^{11}$

Simvastatin $20 \mathrm{mg}$ OD PC (after meal) because diabetic patients have a higher absolute risk of recurrent CHD events and other atherosclerotic events. ${ }^{12}$

Insulin Glargine (Lantus) 100 units/ml 26 units at dinner and Humulin 500 units/ml 8 units TID were given as well. Omeprazole $40 \mathrm{mg}$ OD. PPI which is commonly used in cardiovascular patients for gastric protection when aspirin is given for its antiplatelet actions. ${ }^{13}$ but the patient didn't get aspirin prescription on discharge. Levetiracetam $500 \mathrm{mg}$ oral OD for delirium was given also.

Alcohol misuse leads to a risk of thrombocytopenia, prolonged bleeding times is a risk factor for SDH. ${ }^{14}$ Anticoagulation treatment (including with aspirin or warfarin) is another risk factor. ${ }^{15}$
Five randomized clinical trials have compared aspirin with placebo or no therapy for the prevention of stroke and MI. In women, doses of $50 \mathrm{mg}$, 75 , and $100 \mathrm{mg} /$ day did not significantly decrease the risk of MI, the women appropriate dose therefore must be higher than $100 \mathrm{mg} /$ day. ${ }^{16}$ The elderly group of patients is more prone to having aches and pains and they may use aspirin. Confusion due to salicylate can occur at therapeutic doses while the major manifestation of salicylate toxicity is Delirium. ${ }^{17}$

Extreme care must be used in administering Diazepam Injection, particularly by the intravenous route, to the elderly, or very ill patients, and to those with limited pulmonary reserve because of the possibility that apnea and/or cardiac arrest may occur. Concomitant use of barbiturates, alcohol or other central nervous system depressants increases depression with increased risk of apnea. Resuscitative equipment including that necessary to support respiration should be readily available. $^{18}$ a case was reported where administration of diazepam led to a state of acute delirium. This side effect of diazepam should be kept in mind while dealing with delirium in the geriatric age group. ${ }^{19}$

Benzodiazepines are preferred over neuroleptics for treatment of delirium resulting from alcohol or sedative hypnotic withdrawal. ${ }^{20}$ Use special precaution when using benzodiazepines because they may cause respiratory depression, especially in patients who are elderly with alcoholic intoxication, those with pulmonary problems, or debilitated patients. ${ }^{21}$

The interaction between simvastatin and phenytoin must be considered because decreasing simvastatin serum levels below therapeutic level provided by the minimum recommended is clinically important. ${ }^{22}$

Management of cerebral edema should include subtler approaches such as hyperventilation to $\mathrm{PaCO} 2$ : of 30-35 mm Hg, mannitol + furosemideinduced diuresis and barbiturates, with concurrent intracerebral pressure (ICP) monitoring. ${ }^{23}$ In patients with traumatic pain injury (TBI) Mannitol diuretic is preferred over furosemide because it tends to cause less severe electrolyte imbalances than a loop diuretic. Interestingly, mannitol and furosemide have a synergistic effect when combined; however, this combination tends to cause severe electrolyte disturbances. Hypertonic saline (3-23\%) has generated some interest in the treatment of intracranial hypertension secondary to brain edema because it is thought to be less disruptive to fluid and electrolyte balance than other diuretic agents. In a recent review of the literature, $23 \%$ saline was noted to decrease elevated ICP by nearly $50 \%$ an hour after administration in patients with life-threatening elevations in ICP. ${ }^{24}$

Many studies have shown that physical inactivity is associated with insulin resistance, often leading to type 2 diabetes. In the body, since glucose is used by muscle than other tissues people should aim for at least $30 \mathrm{~min}$ of exercise most days of the week. For best results, people should do both aerobic activities, which use large muscle groups and make the heart beat faster, and muscle strengthening activities. ${ }^{25}$ Other causes of insulin resistance may include ethnicity; certain diseases; hormones; steroid use; some medications; older age; sleep problems, especially sleep apnea; and cigarette smoking. ${ }^{26}$ Belly fat plays a part in developing chronic, or longlasting, inflammation. Scientists have found that complex interactions in fat tissue draw immune cells to the area and trigger low-level chronic inflammation. This inflammation can contribute to the development of insulin resistance, type 2 diabetes, and CVD. A review of the research tells us that insulin sensitivity is actually increased when you lower your weight or body fat percentage. ${ }^{27}$

Researchers are interested in the role vitamin D plays in improving insulin sensitivity and increasing insulin secretion. Studies have reported a link between low vitamin $\mathrm{D}$ and decreased insulin sensitivity. ${ }^{28} \mathrm{~A}$ twoyear vitamin D supplementation trial involving African Americans with T2D found that raising vitamin D levels from $25 \mathrm{ng} / \mathrm{mL}$ to $34 \mathrm{ng} / \mathrm{mL}$ significantly reduced hemoglobin A1c from $9.15 \%$ to $7.98 \% .{ }^{29}$ Patients 
Al-Khateeb and Jamal Alomar: et al.: Pharmaceutical care evaluation of Subdural Hematoma and Delirium case

Table 1: Lab values

\begin{tabular}{cccc}
\hline Lab value & Result & Reference range & Comment \\
\hline Creatinine & $\begin{array}{c}106 \text { micromole } / \mathrm{l} \\
(1.2 \mathrm{mg} / \mathrm{dl})\end{array}$ & $0.7-1.4 \mathrm{mg} / \mathrm{dl}$ & High \\
WBC & $16.1 \times 10^{\wedge} 3$ & $\begin{array}{c}3.9-5.03 \text { million cells/ } \\
\mathrm{mcl}\end{array}$ & High \\
& & $13.5-18 \mathrm{~g} / \mathrm{dL}$ & Low \\
HGB & 10.2 & $135-145 \mathrm{micromole}$ & Low \\
Na Level & 126 & & \\
\hline
\end{tabular}

Table 2: Fasting Blood Glucose readings

\begin{tabular}{ccc}
\hline Dates & FBS - Reading Value & Reference \\
\hline 7th/April & $138 \mathrm{mg} / \mathrm{dl}$ & High \\
8th/ April & $270 \mathrm{mg} / \mathrm{dl}$ & High \\
9th/ April & $208 \mathrm{mg} / \mathrm{dl}$ & High \\
10 th/ April & $403 \mathrm{mg} / \mathrm{dl}$ & High \\
11th/ April & $212 \mathrm{mg} / \mathrm{dl}$ & High \\
12th/ April & $343 \mathrm{mg} / \mathrm{dl}$ & High \\
$13 \mathrm{th} /$ April & $342 \mathrm{mg} / \mathrm{dl}$ & High \\
$14 \mathrm{th} /$ April & $170.6 \mathrm{mg} / \mathrm{dl}$ & High \\
15th/ April & $270 \mathrm{mg} / \mathrm{dl}$ & High \\
16th/ April & $266 \mathrm{mg} / \mathrm{dl}$ & High \\
17th/ April & $230 \mathrm{mg} / \mathrm{dl}$ & High \\
\hline
\end{tabular}

with alcoholism and patients with malnutrition are prone to thiamine and vitamin B-12 deficiency, which can cause delirium. Thiamine Vitamins for alcohol withdrawal should be discussed. ${ }^{30}$

\section{CONCLUSION}

Effective and safe administration of medicines in elderly patients is essential. Standards considering concomitant disease states and medications will ensure and enhance the therapeutic outcomes. Dose adjustment along with monitoring parameters and monitoring of symptoms should be implanted. Resuscitative equipment availability and drug-drug or drug-disease interactions should be more clear in the clinical practice, the use of unnecessary drugs as well might has risk of disease development or symptoms which are already presented in the case. Finally supplements should be considered in treatment plan.

The most important missing approach can be summarized as: Adjustment of the dose of Levetitracetam is according to creatinine clearance especially because the patient is elderly should be considered. Resuscitative equipment including that necessary to support respiration should be readily available in administering Diazepam (IV) Injection. Management of cerebral edema should include concurrent intracerebral pressure (ICP) monitoring. Thiamine (vitamin B-12) deficiency can cause delirium and should be ruled out. Vitamin D supplementation significantly reduced hemoglobin A1c improving insulin sensitivity and increasing insulin secretion.

Hypertonic saline (3-23\%) in the treatment of intracranial hypertension is interesting, with less disruptive to fluid and electrolyte balance. Omeprazole increased risk of pneumonia, an increased risk of bone fractures, and the patient is already with hip fracture and pneumonia.

\section{ACKNOWLEDGEMENT}

None.

\section{CONFLICT OF INTEREST}

No conflict of interest are declared.

\section{ABBREVIATION USED}

CSDH: Chronic subdural haematoma; DVT: Deep vein thrombosis; CAM: Confusion Assessment Method; DSM-III-R: Diagnostic and Statistical Manual of Mental Disorders delirium criteria.

\section{REFERENCES}

1. Fogelholm R, Waltimo O. Epidemiology of chronic subdural haematoma. Acta Neurochir. 1975;32(3-4):247-50.

2. Ellis GL. Subdural haematoma in the elderly. Emerg Med Clin North Am. 1990;8:281-94.

3. Traynelis VC. Chronic subdural haematoma in the elderly. Clin Geriatr Med. 1991;7:583-98.

4. Cho S, Lau SW, Tandon V, Kumi K, Pfuma E, Abernethy DR. Geriatric drug evaluation: where are we now and where should we be in the future?. Arch Intern Med. 2011;171(10):937-40.

5. Wei LA, Fearing MA, Sternberg EJ, Inouye SK. The Confusion Assess ment Method: a systematic review of current usage. J Am Geriatr Soc. 2008;56(5):823-30.

6. Willard RN, Muñiz AE, Chuidian F. Delayed subdural hematoma after receiving enoxaparin for prevention of thromboembolic events from high-risk surgery. Am J Emerg Med. 2012;30(6):1017.e5-8.

7. "DailyMed - KEPPRA- levetiracetam tablet". dailymed.nIm.nih.gov. Retrieved. 2015-11-04.

8. Sabatelli F, Patel R, Mann PA, Mendrick CA, Norris CC. In vitro Activities of Posaconazole, Fluconazole, Itraconazole, Voriconazole, and Amphotericin B against a Large Collection of Clinically Important Molds and Yeasts. Antimicrob Agents Chemother. 2006;50(6):2009-15

9. Devlin JW, Roberts RJ, Fong JJ, Skrobik Y, Riker RR. Efficacy and safety of quetiapine in critically ill patients with delirium: a prospective, multicenter randomized, double-blind, placebo-controlled pilot study. Crit Care Med. 2010;38(2):419-27.

10. "Furosemide". The American Society of Health-System Pharmacists. Retrieved Oct. 23, 2015

11. Dayalu P, Chou KL. Antipsychotic-induced extrapyramidal symptoms and their management. Expert Opin Pharmacother. 2008;9(9):1451-62.

12. Haffner SM. Management of dyslipidemia in adults with diabetes (Technical Review). Diabetes Care. 1998;21:160-78.

13. Agewall S, Cattaneo M, Collet JP, Andreotti F, Lip GY, Verheugt FW. "Expert position paper on the use of proton pump inhibitors in patients with cardiovascular disease and antithrombotic therapy". Eur Heart J. 2013;34(23):1708-13, 1713a-1713b.

14. Sim YW, Min KS, Lee MS, Kim YG, Kim DH. Recent changes in risk factors of chronic subdural hematoma. J Korean Neurosurg Soc. 2012;52(3):234-9.

15. Rust T, Kiemer N, Erasmus A. Chronic subdural haematomas and anticoagulation or anti-thrombotic therapy. J Clin Neurosci. 2006;13(8):823-7.

16. Dalen JE, Aspirin to prevent heart attack and stroke: what's the right dose, Am J Med. 2006;119(3):198-202.

17. Moore AR., O'Keeffe ST. Drug-induced cognitive impairment in the elderly. Drugs Aging. 1999;15:15-28.

18. Thomson Healthcare (Micromedex) (March 2000). "Diazepam". Prescription Drug Information. Drugs.com. Retrieved 2006-03-11.

19. Nannapaneni DT, Gupta A VSSS, Reddy MI, Sarva R Ch. Synthesis, Characterization, and Biological Evaluation of Benzimidazole Derivatives as Potential Anxiolytics. JYP. 2010;2(3):273-9.

20. Muzyk AJ, Fowler JA, Norwood DK, Chilipko A. Role of $\alpha 2$-agonists in the treatment of acute alcohol withdrawal. Ann Pharmacother. 2011;45(5):649-57.

21. Martel M, Sterzinger A, Miner J, Clinton J, Biros M. Management of acute undifferentiated agitation in the emergency department: a randomized doubleblind trial of droperidol, ziprasidone, and midazolam. Acad Emerg Med. 2005;12(12):1167-72

22. Yau A, Abd Aziz AB, Haque M. Knowledge, Attitude and Practice Concerning Pharmacogenomics among Pharmacists: A Systematic Review. JYP. 2015;7(3):145-54

23. Bendo AA. "Anesthesia for Neurosurgery, Chapter 28, in: Clinical Anesthesia, $4^{\text {th }}$ ed, Barash, PG, Cullen, BF, Stoelting, RK (eds) pp 777-789, Philadelphia, PA. Lippincott Williams \& Wilkins, 2001.

24. Lazaridis C, Neyens R, Bodle J, DeSantis SM. High-osmolarity saline in neurocritical care: systematic review and meta-analysis. Crit Care Med 2013;41(5):1353-60

25. Willis LH, Slentz CA, Bateman LA, Shields AT, Piner LW, Effects of aerobic and/or resistance training on body mass and fat mass in overweight or obese 
Al-Khateeb and Jamal Alomar: et al.: Pharmaceutical care evaluation of Subdural Hematoma and Delirium case

adults. J Appl Physiol. 2012:15;113(12):1831-7.

26. Willi C, Bodenmann P, Ghali WA, Faris PD, Cornuz J. Active smoking and the risk of type 2 diabetes: a systematic review and meta-analysis. JAMA. 2007;298(22):2654-64.

27. Chary KV, Swaminathan P. Insulinophobia: Existence of an Infamous Reality In Primary Health Care. JYP. 2016;8(2):141-3.

28. Alomar MJ, Al Khouri MC. Assessing the Magnitude and Effect of Various Risk
Factors Associated with Vitamin D Deficiency among Females in the UAE. JYP. 2015;7(4):296-302.

29. Green RT, Gambhir KK, Nunlee-Bland G, Odonkor WA, Ganta VA. Maintenance of long-term adequate levels of vitamin d lowers HbA1c in African American patients with type 2 diabetes. Ethn Dis. 2014;24(3):335-41.

30. Osiezagha K, Ali S, Freeman C, Barker NC, Jabeen S, Maitra S. Thiamine Deficiency and Delirium, Innov Clin Neurosci. 2013;10(4):26-32.

Article History: Submission Date: 10-10-16; Received Date: 25-10-16; Acceptance Date: 28-12-16.

Cite this article: Al-Khateeb A, Alomar MJ. Subdural Hematoma and Delirium case evaluation in elderly patients. J Young Pharm. $2017 ; 9(2): 299-302$. 